mens. My experience with transfusions in cases of infections leads me to believe that they act only as a supportive measure. In cases of infection, the lylood itself is usually bactericidal. What we need are methods for developing tissue immunity. Some observers have been misled into thinking that transfusions act in a bactericidal fashion because the bacteria often disappear from the blood after transfusion. However, this usually only happens if there has been a reaction after the transfusion. When, in a case of general infection, a reaction occurs after transfusion, the blood is apt to become free of bacteria for a day or two. The same thing will happen, however, if you get a reaction after injecting a sa1t solution. In some interesting studies made in cases of streptococcus endocarditis by Dr. Epstein, with a colloidal preparation of iodin, the bacteria would sometimes disappear from the blood for three or four days, and then return. Too much stress cannot be laid on the proper examination of the donor. It is not sufficient to make the tests-the donor must be examined from head to foot. This is of the greatest importance in excluding all lesions of syphilis unaccompanied by a positive Wassermann reaction. To avoid the effects of putting in large amounts of blood, it is important to cut down the fluids before the transfusion is performed. In cases of cardiac disease, especially mitral stenosis, great caution must be used as regards the amounts of blood given. The cough symptom as described by Dr. Unger is very valuable. The two most valuable methods are the Unger and the citrate methods. The citrate method appears to cause more reactions than the Unger method; in febrile cases, both methods are apt to produce chills and rises of temperature. In patients in very poor condition from toxic diseases, in which it is important to avoid a chill, the Unger method may be preferable. It is necessary that studies be made as regards the effects of and the contraindications to the use of transfusions in cases accompanied by various renal conditions. I know of two instances in which a citrate transfusion caused a temporary blocking of the kidney. It may be found that the same will occur in cases of renal disease when other forms of transfusions are used.

\section{FOREIGN BODIES WITHIN THE EYEBALL *}

JOHN O. MCREYNOLDS, M.S., M.D., LL.D. DALLAS, TEXAS

The literature on this subject has been so thoroughly reviewed by Würdemann, Ramsey and others that we may pass at once to the practical consideration of the various points that naturally arise for decision and action; and if we can succeed in so presenting the most important problems as to develop a full discussion, the result would be the ripened conclusions of American ophthalmology.

The whole matter, so far as the patient and the surgeon are concerned, can be resolved into the three primary questions :

1. What are the location and character of the foreign body?

2. What are the proposed measures of relief?

3 . What will be the probable immediate and remote results?

\section{LOCATION AND CHARACTER OF FOREIGN BODY}

The answer to the first question involves a careful analysis of many circumstances and facts. Is the foreign body actually within the globe, or has it been withdrawn through the point of entrance, or has it gone entirely through the globe and found lodgment in the

* Read before the Section on Ophthalmology at the Seventieth Annual Session of the American Medical Association, Atlantic City, N. J., June, 1919. postocular tissues? These questions are fundamental and yet may involve perplexing difficulties. The media may be so clouded by hemorrhage or corneal, lenticular or vitreous opacities that a satisfactory examination with the ophthalmoscope or with other instruments for direct inspection would be impossible. The foreign body may be of such a nature as to offer no resistance to the roentgen rays, or it may be so minute as to cast no perceptible shadow, or it may be nonmagnetic and hence would give no response to the magnet or sideroscope. Here it is that the history may be of the greatest value, as some illustrative cases will emphasize.

We have all many times encountered injured eyes in which it was difficult to determine whether the foreign body was just within or just without the sclera, especially when the foreign body was evidently driven with considerable force, or was small, or was not impervious to the roentgen rays. Injuries of this kind are, frequently, bird shot injuries with intraocular hemorrhage; and, fortunately, the roentgen ray will usually be sufficient to determine the location. Occasionally the presence of postocular hemorrhage with proptosis will point to traumatism behind the globe and will confirm the roentgen-ray findings. In such cases, if the traumatism is not excessive we may avail ourselves of the ten-day period of probation admissible in all cases of eye injury without risk of sympathetic ophthalmia, and many illuminating features may develop. The postocular hemorrhage after a short time may show as a dark discoloration about the lids, and the swelling will subside and the inflammatory features recede to such a degree that we may safely persist in our efforts to save an eye that might have been sacrificed under the suspicion of a retained foreign body. As a rule, small aseptic bodies, passing entirely through the eyeball and lodging in the retro bulbar cellular tissue, may be allowed to remain, and they generally give rise to no future trouble.

Some regard may be paid to the propelling force and to the distance traversed by the foreign body before entering the eye as bearing on the question whether it has lodged within the eye. If it is within the globe and cannot be extracted, an enucleation or evisceration will be the probable result sooner or later. If it has passed entirely through the globe, the prognosis will depend largely on its path. If it enters the sclera posterior to the ciliary region and in its passage has produced very little hemorrhage and no injury to the macular region, the result may be favorable as to the preservation of vision. If, however, it passes through the lens or ciliary body with much laceration of the tissues, the primary wound will probably be followed by inflammatory changes leading to loss of the eyeball.

Having determined the location of the foreign body to be within the globe, we must next consider the toleration for such bodies by the different anatomic structures, which vary greatly in this respect, and also the chemical and bacteriologic character of the foreign body. Generally, those tissues which are most abundantly supplied with nerves and blood vessels are the least tolerant of foreign invasion. The iris and ciliary body especially resent the presence of an intruder, while the lens, if slightly wounded, may indefinitely accommodate a sterile particle of small magnitude. The posterior segment of the retina and choroid may, by throwing around the foreign body a protecting cov- 
ering of plastic exudate, bear the intruder for a considerable time, while the vitrcous with its sluggish reaction may allow the foreign body to float freely in its mass. The chenical nature of the foreign body greatly influences its tendency to produce reaction; thus, glass may be harbored kindly, while copper will provoke a prompt and decided response. But the most important feature in the character of a foreign body relates to its bacteriologic status. All portions of the internal structures of the eyeball offer good media for the propagation of various micro-organisms, but many of these bodies before entering the eye have been sterilized by heat, and a study of this factor may be helpful in arriving at a wise conclusion. Much depends on the virulence of the organisms that may be introduced with the foreign body. If an active infectious process is once established within an eye containing a foreign body, the prognosis is more unfavorable. I have, however, seen cases of vitreous infection, demonstrated as such by microscopic findings, in which a rather extensive intra-ocular operation succeeded in mechanically removing all of the infected tissue, with the preservation of the globe.

With reference to the size, we might say that the larger foreign bodies involve greater hazard by virtue of the traumatism which they infict on their entrance, although the promptness and ease with which they are generally removed would be factors in their favor.

It has so happened in my experience that eyes wounded with glass do not as a rule contain the pieces of glass. The wounds are frequentiy badly lacerated, but may yield a fairly good result.

As bearing on the nature of a retained foreign body, the presence of a distinct siderosis is quite characteristic of a ferruginous body which has been undergoing partial or complete absorption.

\section{MEASLRES OF RELIEF}

The method of removing a foreign body from the eye depends entirely on its character, size and location. A natural division as to character would be magnetic and nonmagnetic, the former being nore easily removed because of the availability of magnetic influence. Much has been written about the kind of magnet that is most efficient. The dictum of $\mathrm{Haab}$ that "He who has the strongest magnet will get the best results" must be taken with some modification.

The facility with which the magnet may be manipulated, thus bringing the electrode into the most favorable approximation to the foreign body, must constitute a most important factor. My personal preference is for the improved Sweet magnet, which has the usual power requisite for attracting magnetic bodies, and in addition its electrode can be brought in contact with the foreign body in any part of the globe. The Haab magnet, the Victor magnet, the intrapolar magnet and other large magnets are especially applicable to those cases in which it is sought to remove the foreign body through the anterior chamber in accordance with the views advocated by Haab.

Since the introduction of the more accurate methods of localization by the roentgen ray, the relative value of the medium sized magnets as compared with the giant magnets has been advanced. I think no one now would prefer the giant magnet in the case of large foreign bodies, on account of the violent force developed, which might do harm to uninjured structures; but it has some advantage in those cases in which the foreign body has not been accurately located and in which it is situated in the anterior segment of the globe. Even in the case of foreign magnetic bodies in the vitreous, after a scleral incision, the point of the siant inagnet may be applied to the opening of the wound, either alone or in conjunction with magnetized probes, forceps or scissors; and if unsuccessful, this procedure may then be followed by the use of the Sweet magnet, which has the advantage of greater ease in accurate manipulation.

It is a matter of considerable importance to decide wisely as to the route to be adopted in the removal of a foreign body, whether by the anterior or the posterior route. And it must be admitted that there are advantages in both methods, and the difficulty is in discriminating between the two in each individual case. My own experience has emphasized the safety and practicability of removing foreign bodies through a scleral incision whenever the foreign body is easily accessible by this route. I have not seen retinal detachment at the seat of the incision follow such a procedure, and when detachment has occurred it was due to the inflammatory process induced by the presence of the foreign body and by the original traumatism.

On account of the dangers of iridocyclitis, with a possible transferred ophthalmitis, I have a profound respect for the anterior segment of the eyeball, and would prefer to employ no procedure which would add anything to the traumatism in this region. Unless the conditions are such that the foreign body can be smoothly extracted by this route, I should prefer to invade the posterior segment of the globe rather than the ciliary zone.

\section{RESULTS}

The immediate and remote results must have regard, not only to the injured eye, but also to the fellow eye. In general terms, we might say that the immediate result in the injured eye will be favorably influenced by the following factors: accurate localization, the early removal of the foreign body, the minimum of traumatism by the flight of the missile and the subsequent operative procedure, the noninvolvement of the ciliary body, the lens and the macula region, and the negative chemical and bacteriologic character of the foreign body.

It must be remembered that the victory has not been won when the foreign body has been brilliantly extracted from the interior of the globe. We must still await, some times through weeks and months and years, the final processes of degeneration, retinal detachment and clouded media which may bring but grief and pain for promised joy.

We must remember not only that the insidious danger of sympathetic ophthalmia lurks in the presence of the foreign intruder, but also that the seeds of disaster are sometimes sown in its pathway, springing up into that fateful fruitage which brings total blindness with its blighting brood of unavailing regrets.

\section{ILLUSTRATIVE CASES}

The purpose of this report of Cases 1,2 and 3 is to emphasize some important features pertaining to the localization, the extraction and the final result in cases of exceedingly minute foreign bodies within the globe. We have always recognized the full significance of the retention within the eyeball of all foreign bodies of a magnitude capable of being determined by the ordinary methods; but some special consideration might be given 
to the behavior of those particles so extremely small as to cast no shadow, after the skilful application of the most powerful and efficient roentgen light.

As to localization, I might say that we have felt since the introduction of the Sweet method that all magnetic metallic bodies could be certainly located with accuracy; but $I$ have encountered some recent cases that

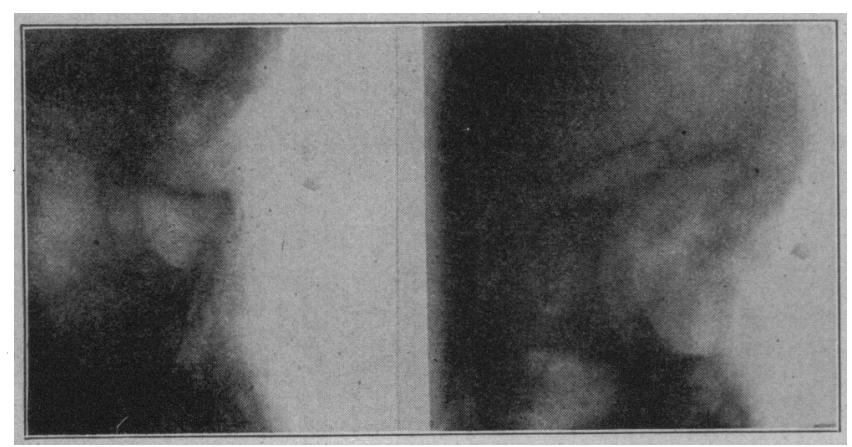

Fig. 1 (Case 3).-Roentgenographic appearance of the eye before (left) and after (right) attempt at extraction of the foreign body. The first picture showed a distinct shadow of a foreign body located as shown in the diagram, Figure 2. The second picture, taken some time after the attempt at removal with the giant magnet, shows no foreign body, but the patient had a complete secondary cataract with a marked degree of siderosis.

show that some particles of this kind may elude the roentgen ray and still be clearly perceived by the ophthalmoscope and extracted by the giant magnet. The cases were examined by roentgenologists of unquestioned ability and extensive experience, who have repeatedly rendered me the most valuable assistance in the localization of very minute masses of foreign matter within the globe, and I esteem it a pleasure to bear testimony, unreservedly, to their patience and skill.

CAsE 1.-Mr. R. of Weatherford, Texas, came to me with the history of a slowly developing cataract in the right eye, beginning some weeks after the supposed receipt of an injury to the eye four months previously. He had been carefully examined by a competent ophthalmologist who reported tratimatic cataract from concussion, a condition which we all frequently have occasion to observe.

On my first examination with lenses of high power, I discovered on the temporal side of the sphincter pupillae a minute opening through the iris tissue, in diameter equal to the crosssection of a cambric needle. This opening at first appeared dark in color, like a speck of pigment, but on lateral illumination I could see the opaque lens substance through this minute aperture. I then applied the giant magnet directly to the corresponding area of the cornea, and the lens and iris were observed to advance slightly. I described the occurrence to the roentgenologist, and requested a close examination of the anterior segment of the globe. After repeated trials, no foreign body could be definitely located. I then invited the foentgenologist to be present at the proposed extraction of the steel. An incision was made along the corresponding arc of the limbus, and through this incision I passed a pair of fine steel iris forceps, and up to the minute opening in the iris above described. Then, while I held very firmly to the forceps, the tip of the giant magnet was brought in contact with the forceps at the point of entrance of the latter into the anterior chamber. Then the current was turned on and the magnet and attached iris forceps were gently withdrawn from the eye, bringing out of the lens and through the needle hole in the iris an exceedingly delicate piece of steel. With the most accurate jeweler's scales available the foreign body was declared imponderable, but was estimated to weigh approximately onethousandth of a carat: Its length was $2.2 \mathrm{~mm}$., its breadth was $0.2 \mathrm{~mm}$. and its thickness was that of the finest thread. The accident occurred while the patient was standing a few feet from one of his employees, who was using a chisel on a piece of marble. The vision was not at first impaired, and the pain and reaction were insignificant; but at the time of my examination, the lens was completely opaque. It is interesting that so slender and so delicate a piece of metal should be driven such a distance and with such force as to become completely embedded in the lens and yet remain unbroken by its impact.

The indications are that a cataract extraction at any subsequent time will secure for the eye useful reading vision.

Case 2.-Mr. L. A. of Dallas was operated on in conjunction with my partner, Dr. Seay. The history clearly traced the injury to a blow which the patient struck on a chisel, and the vision became at once impaired, but gradually cleared up, so that a minute piece of metal was distinctly seen with the ophthalmoscope near the center of the vitreous chamber. The trabeculae of the vitreous were broken down in the lower segment of the vitreous, thus allowing limited movement of the metal when the eyeball was quickly rotated.

The roentgen ray was called into requisition for confirmation, as a question had arisen as to whether this movable mass was of metal or of pigment. No shadow whatever was developed, and the magnet failed to make any impression on the mass. But the ophthalmoscopic picture was so conclusive that we made an incision.in the region of the equator and between the external and inferior rectus muscles. Through this scleral opening we passed into the globe delicate steel iris forceps until their points approximated the foreign mass. Then we applied the tip of the giant magnet to the forceps at the point of entrance of the latter into the vitreous chamber. The current was then turned on and the magnet and forceps gently withdrawn from the eye, bringing along a very minute, polyhedral piece of steel. The eye was again examined with the ophthalmoscope, and a piece of metal was discovered in the central area of the vitreous. So we reinserted the forceps and applied the magnet as before; when they were withdrawn from the eye, the remaining piece of steel was found attached to the distal extremities of the forceps.

The ophthalmoscopic examination showing no more foreign materia 1, a double con-

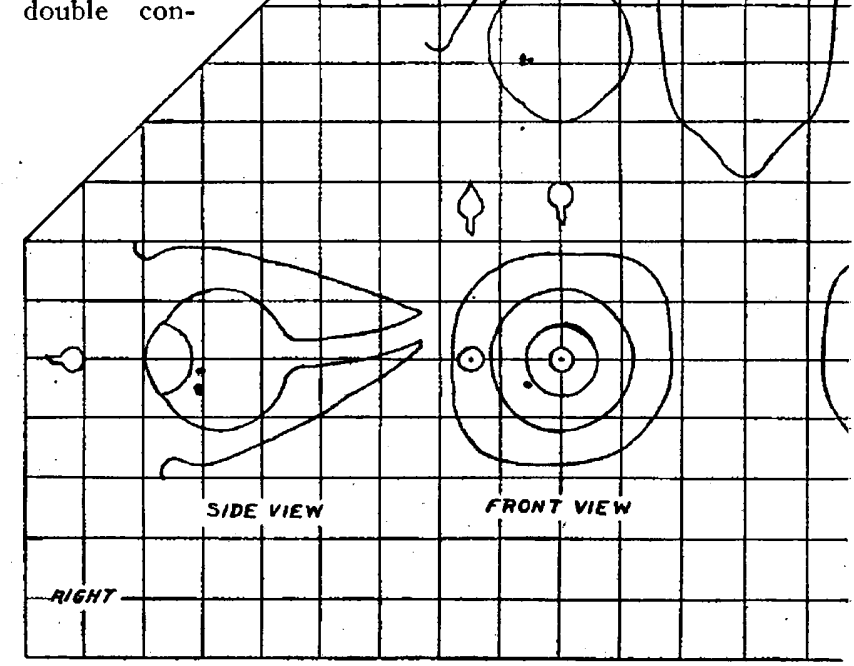

Fig. 2 (Case 3).-Diagrams showing the location of the foreign body.

junctival flap was carried by mattress sutures over the scleral wound, and the usual surgical precautions followed. After a lapse of more than ten months, the media are still clear and the vision is normal.

CASE 3.-Mr. G. H. of Groesbeck, Texas, was struck in the eye, July 5,1915 , by a piece of steel, causing pain and immediate reduction of the vision. The vision then improved; and when the patient was seen, July 6 , by my partner, Dr. Seay, 
the vision was $20 / 40$. The roentgenogram at that time showed a distinct shadow of a foreign body $1 \mathrm{~mm}$. in diameter and situated $12 \mathrm{~mm}$. back of the center of the cornea. Dr. Seay applied the giant magnet to the point of entrance of the steel without producing any distinct impression (Figs. 1 and 2).

An operation for extraction was then advised, but the patient preferred delay because of the existence of useful vision and the absence of pain.

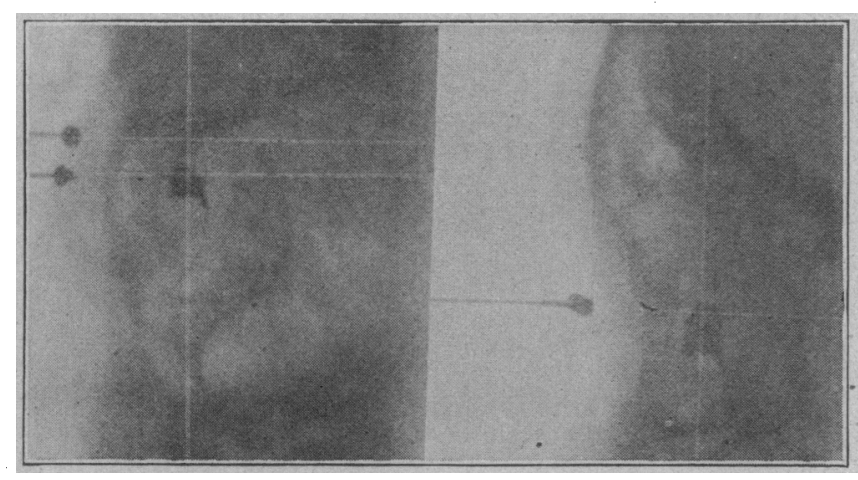

Fig. 3 (Case 4).-Roentgenographic location and appearance of the foreign body in the eye.

Recently the patient presented himself with a complete secondary cataract and with a marked degree of siderosis, converting a light blue iris into a rusty brown, with brownish deposits on the lens. The roentgenogram by the same expert as before failed to show any foreign body whatever. We accordingly extracted the opaque lens so that now through the moderately clear media we can confirm the roentgenographic findings of complete absence of any foreign body, and useful vision has been secured for the injured eye.

The indications are that the piece of iron had undergone complete solution in the vitreous, and the resulting salts of iron had become deposited in the various intra-ocular tissues. The case is worthy of record as bearing on the question of the solubility of metals in the humors of the eyes and on the further question of the infuence of these resulting salts on the transparency of the lens, the substance of which was not stained by the salts of iron but was completely protected by the capsule. The lenticular opacity was evidently due, not to direct injury but to nutritional changes in the uveal tract. The final result in all cases must await the action of those gradual processes of vitreous contraction and retinal detachment which may supervene even after the lapse of many months to mar the satisfaction of our best achievements.

Cases 4, 5 and 6 were extensive injuries, and they serve to illustrate the possibilities in such cases even in the presence of definite infection.

Case 4,-Master C. C. of Greenville, Texas, aged 14 years, exploded a copper shell by striking it with an ax. A piece of the margin of the shell from which the ball and powder had been extracted was driven into the eyeball. This occurred, May 2, 1911. The wound in the lid was repaired by Dr. C. E. Cantrell, who sent the patient to Dallas for operation, which was performed, May 3, after an accurate roentgenogram had been made by Dr. J. M. Martin. The weight of the piece of copper was 3 grains, and the dimensions were 5 by $9 \mathrm{~mm}$. The location was $3 \mathrm{~mm}$. below the horizontal plane of the cornea, $10 \mathrm{~mm}$. to the temporal side of the vertical plane of the cornea, and $8 \mathrm{~mm}$. back of its center. The roentgenogram and diagram (Figs. 3 and 4 ) are herewith presented. The wound in the sclera began at the upper and outer portion of the limbus and extended through the ciliary region for one-eighth inch; the pupil was irregular and vision reduced to the perception of fingers at 3 feet. A new incision was made through the sclera below the external rectus over the situation of the foreign body, which was extracted with forceps, together with the contiguous portions of the vitreous, which had become opaque and slightly yellow from the inflammatory process, which was infectious in character as shown by the microscope. Both wounds were then freed from the adjacent uveal tissue, and closed with a double layer of conjunctiva secured in position by mattress sutures. An interesting feature is that the infectious process in the vitreous did not extend, evidently because the infected portions were freely removed with the foreign body embedded therein. The normal form and comfort of the eyeball have been maintained, and the patient has since graduated with honor at the Virginia Military Institute and has played his part in the military affairs of his country.

The chief lesson taught by this experience is the value of freely removing infected vitreous surrounding a retained foreign body rather than allowing it to remain within the globe. It is simply an extension of the general surgical principles so well established during the war, but which perhaps have not been so widely accepted with reference to the vitreous humor, which we have sometimes been too uncompromising in preserving.

CASE 5.-Ben McC. of Cleburne, Texas, was struck in the eye by a piece of steel, Dec. 25, 1917, which was accurately located by Dr. Bond of Fort Worth and Dr. Martin of Dallas as being $7 \mathrm{~mm}$. above the horizontal plane of the cornea, $3 \mathrm{~mm}$. to the temporal side of the vertical plane, and $13 \mathrm{~mm}$. back of the center of the cornea (Fig. 5). The dimensions were 1.5 by $7 \mathrm{~mm}$. Operation was performed, December 28 . A scleral incision was made over the site of the foreign body, which was extracted with the magnet;

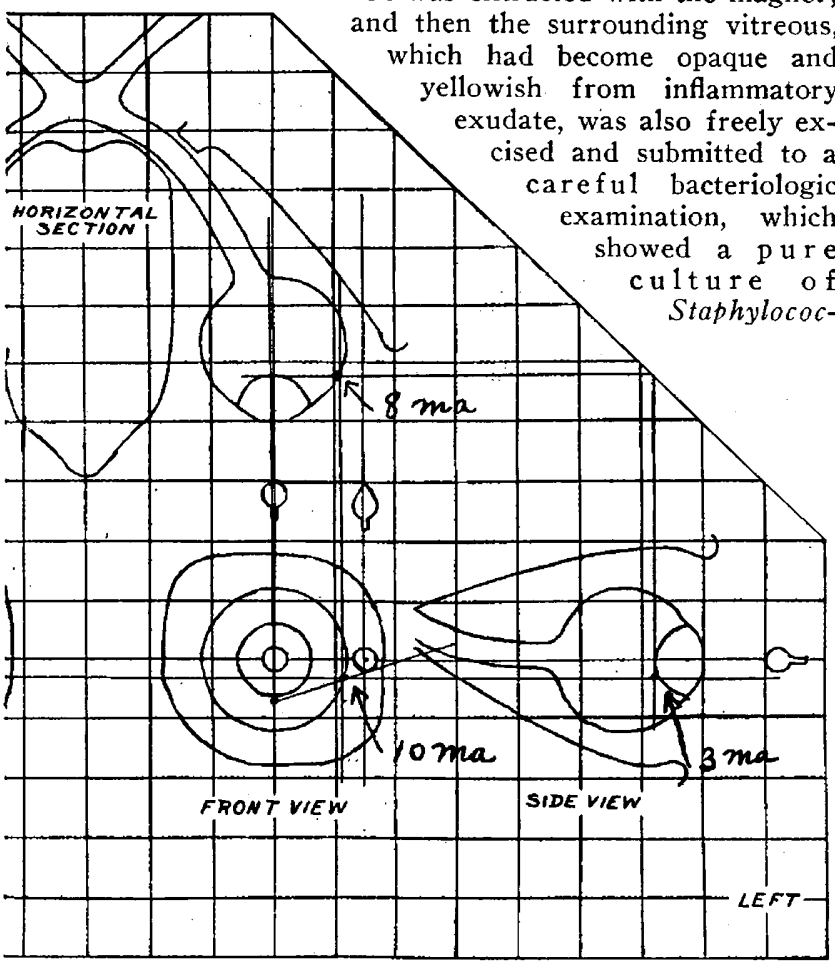

Fig. 4 (Case 4).-Diagrams showing the location of the foreign body in three planes.

cus albus, as also did the piece of steel and an excised piece of the injured iris. The wound was closed by double layers of conjunctiva held in position by mattress sutures, a method which I have used for many years with great satisfaction. It is conveniently and aptly designated as the double breasted coat conjunctival covering. Its advantages were fully described by Dr. Lee Mastin Francis in a paper before this 
section some years ago. The wound healed without any unfavorable manifestations, and presents a reasonably satisfactory appearance, as indicated by the photograph (Fig. 7).

The method employed in excising the opaque infected vitreous consisted in grasping the tenacious exudate with forceps and gently drawing it through the wound, catching successively

new holds on the infected tissue with curved iris forceps, somewhat after the manner of drawing a bucket from a well with a rope, continuing the procedure as long as opaque

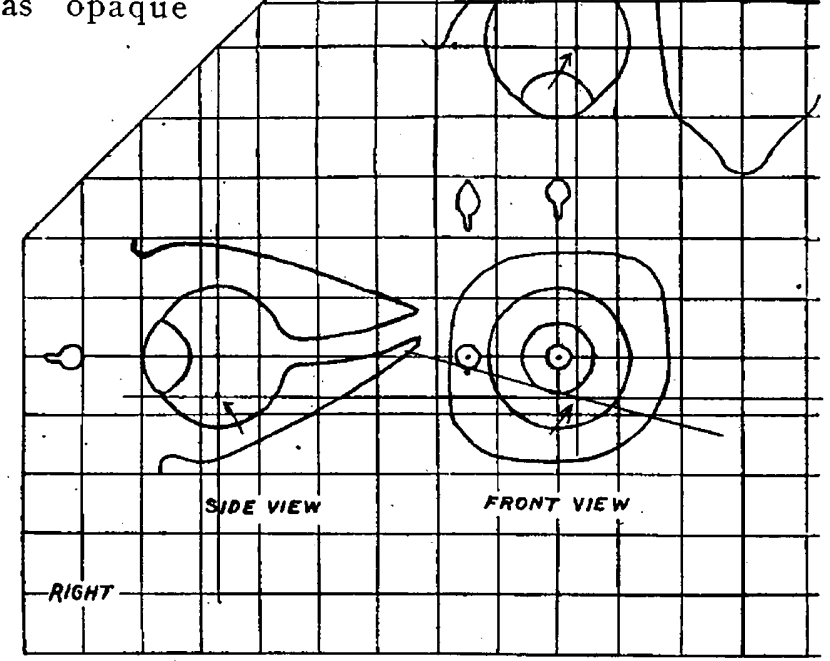

Fig. 5 (Case 5).-Diagrams showing the location of the foreign body in three planes.

vitreous presented. My feeling in the matter is that no good can result from leaving in the eye in iected material, and that the small loss of vitreous involved is easily compensated for by the improved bacteriologic status of the eye in the process of healing. I will add in this connection that in all injured eyes, when I am confronted with the possibility of transferred ophtlualmitis during my efforts to save a severely injured eye, $I$ am in the habit of adopting a measure suggested by our distinguished confrère, Dr. Harold Gifford-saturating the system with salicylates before any sympathetic manifestations appear.

CASE 6.-Mr. B. of Dallas County was, in conjunction with another man, arranging to blast some rock in excavating for a cistern. The discharge of giant powder occurred prematurely, killing instantly the comrade of the patient, and inflicting on the latter the injuries now to be described. When the patient was brought to me two days after the accident, the left globe had been reduced to a perfectly disorganized pulp which admitted of no rational procedure but enucleation, which was accordingly performed. The right globe was perforated in two places by lacerated wounds, and an examination revealed the presence of three pieces of rock within the eyeball, one piece being about half as large as the nail of the little finger. The eye was considerably inflamed and evidently infected, as shown by the character of the discharge. But as the fellow eye was utterly lost and the only possibility of .vision depended on the eye not totally gone, I decided to make the most of a poor opportunity. So, after as thorough disinfection of the injured organ as the circumstances would permit, I made an incision into the globe to an extent greater than half of the circumference of the cornea, in order to be able to reach the scattered fragments of rock which had lacerated and had become embedded in the iris. Unfortunately, the difficulties encountered by the surgeon in dealing with fragments of rock within the globe are much greater than in the case of steel bodies, because the latter can be extracted by the aid of various forms of the electromagnet. And fragments of rock are much more difficult to handle successfully than pieces of wood, because the increased weight of the former is such that when the globe is opened they tend to make a dive for the deeper regions of the vitreous. In this case it was necessary to remove large areas of the lacerated iris in order to be sure of the fragments of rock. The extraction of the rocks and the removal of the injured iris we accomplished by the combined use of hooks and forceps. After the operation the lids were kept closed with light compresses saturated in cool boric acid solution, and at frequent intervals instillations of a mydriatic were made and lotions of mild antiseptics employed. After a few weeks the patient was discharged from St. Paul's Sanitarium with ability to read ordinary type.

In Cases 7, 8 and 9, the foreign body was allowed to remain in the eye for a considerable time, and farled to respond to any measures but the intra-ocular application of magnetic electrodes.

CASE 7.-Mr. W. B. C. of Dallas was struck in the eye by a piece of steel which I present herewith, together with the roentgenograms (Fig. 8) taken in advance of the operation, which was performed eight weeks after the injury. The weight of the steel is $1 / 100$ carat, and the location was $6 \mathrm{~mm}$. below the horizontal plane of the cornea, $6 \mathrm{~mm}$. to the nasal side of the vertical plane of the cornea and $9 \mathrm{~mm}$. back of its center. There was a circumscribed corneal opacity surrounding the track of the steel, and vision amounted to dim perception of fingers. The iris had closed up the anterior capsular opening produced by the entrance of the steel into the lens, and had thus restricted the access of aqueous to the lens substance with consequent limitation of the opaque zone. An incision along the limbus was made and the iris drawn away from the lens with iris forceps, exposing the point of entrance of the steel. An electrode of the improved Sweet magnet was introduced into the opening thus disclosed. The current was turned on and the magnet with the attached piece of steel removed. The eye, which had continued to be irritable before the operation, now quieted down completely, and a subsequent cataract extraction should result in usefu? vision.

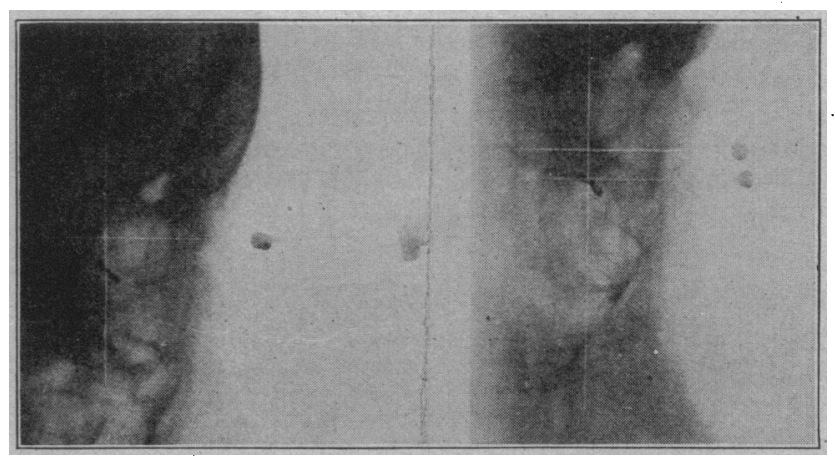

Fig. 6 (Case 5).-Roentgenographic appearance of foreign body and

This illustrates the toleration of the lens for foreign bodies and the action of the iris in limiting the extent of lenticular opacity by preventing the free access of aqueous to the lens substance. The application of the giant magnet to the cornea failed to develop any response, while the direct contact with the electrode of the Sweet magnet was effective, showing that even in the case of foreign bodies located in the anterior seg- 
ment of the eye, the giant magnet applied according to the method of Haab cannot always secure the best result.

CASE 8.-Mr. J. C. A. of Clarendon, Texas, was struck in the eye with a piece of steel three years previously, and the foreign body was located by a roentgenogram near the pos-

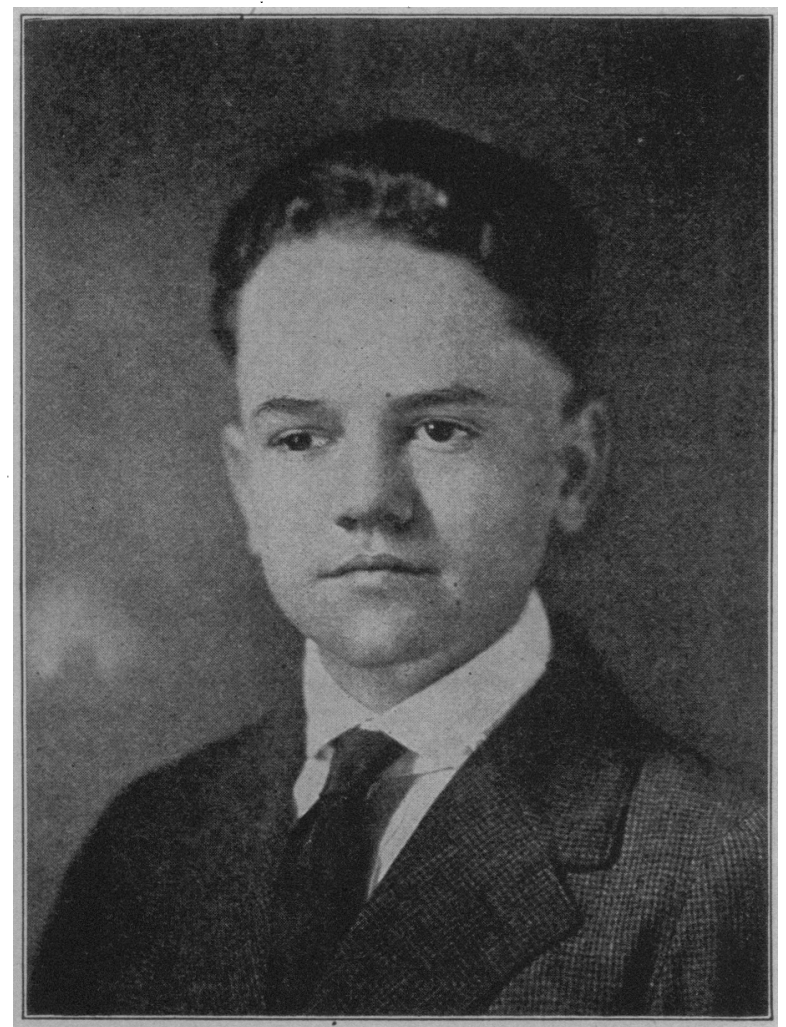

Fig. 7 (Case 5).-Appearance of patient after operation.

terior pole of the eye embedded in the retina.. As the lens was cataractous, it was extracted in the usual way and immediately an iron probe was passed through the corneal wound, through the pupillary space, through the vitreous, until its point was approximately in contact with the foreign body. Then the electrode of the giant magnet was applied to the probe at its point of entrance into the cornea, the current was turned on, and the magnet and probe gently withdrawn, together with the foreign body attached to the distal extremity of the probe. The eye healed without trouble and for some months retained useful vision, after which the patient passed out of observation.

The history of this case shows the feasibility of utilizing the pupillary space as a doorway through which we may safely reach the vitreous when an extraction of the lens is necessary. I think this route for the introduction of magnetized probes has not been widely employed; but it offers an avenue that is worthy of our consideration.

CASE 9.-Mr. E. D. of Dallas, Texas, aged 35, was struck in the eye in 1905 by a piece of steel, and the vision was lost at once. Confrères failed to locate any foreign body, and the eye remained fairly quiet for three years, when photophobia and other manifestations of sympathetic weakness in the good eye developed, while the injured eye was cataractous and showed a marked degree of siderosis.

The piece of steel was located (by the roentgen ray) near the posterior pole, embedded in the retina. The lens was extracted and an iron probe passed through the corneal wound, through the pupillary space, and through the vitreous until it approximated the foreign body. The electrode of the giant magnet was applied to the probe at its entrance into the anterior chamber, the current was turned on and then the magnet, probe, and foreign body were gently withdrawn. The healing process was uneventful and the patient retained useful vision for several years, when the degenerative changes progressed to the point of abolition of vision in the injured eye, although the fellow eye has been free from indications of sympathetic involvement.

CASE 10.-Lieutenant S. of Love Field, an aviator, was referred to me by the post surgeon, Major Earthman, within a few hours after the receipt of an injury which was occasioned by the impact of some foreign body driven by the tremendous force of the propeller. Examination showed that a small foreign body about the size of a duck shot had penetrated the upper lid and had entered the globe in the superior segment of the ciliary zone. There was a prolapse of uveal tissue, and blood filled the anterior chamber, with immediate loss of vision. Apparently a foreign body was either within the eyeball or had passed on through into the retrobulbar region. The roentgen ray showed absolutely nothing, but this could have been explained by the hypothesis that the foreign body was not impervious to the roentgen rays. Nevertheless, as the danger of sympathetic involvement could not reasonably be apprehended within ten days, it was safe to use conservative measures, so the protruding uveal tissue was removed and the usual surgical measures employed for a few days, when the hemorthage became absorbed and the lens was found to be clear, the fundus normal and the vitreous presented a few floating remnants of the previous hemorrhage, which subsequently became completely absorbed. The eye was free from pain or suspicious inflammatory changes, and will probably remain a safe and useful organ of vision, the degree at present being $20 / 30$.

What evidently occurred at the time of the injury was that the foreign body which struck the eye had a sharp point, which permitted a partial penetration which was limited by the size of the foreign body and was immediately spontaneously withdrawn, thus presenting a punctured wound without the retention of a foreign body within the globe. This illustrates the necessity for the utmost conservatism in differentiating retained foreign bodies from punctured wounds presenting many circumstances and appearances that might obtain in either condition.

In connection with extensive wounds of the corned produced by the entrance of foreign bodies, something

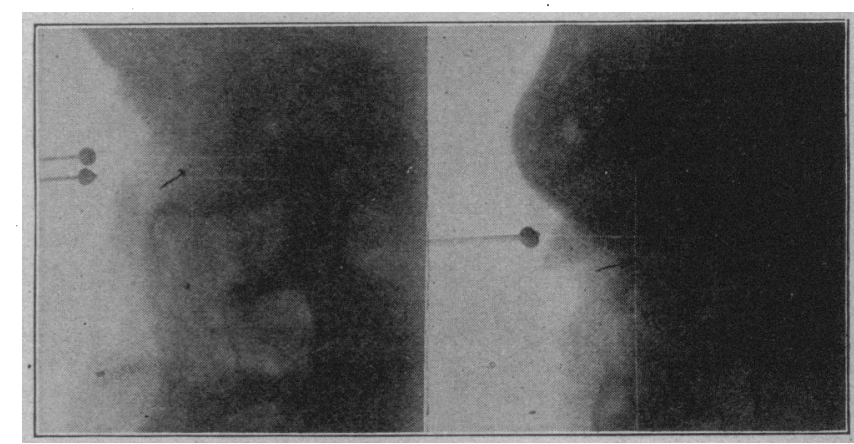

Fig. 8 (Case 7).-Roentgenographic appearance of the eye and orbit just prior to the operation for foreign body, which was performed eight weeks after the injury.

might be said concerning the closure of these wounds after the foreign bodies have been removed.

CASE 11.-The procedure can be illustrated by the case of a young woman, Miss M. N., whose eye was cut wide open by glass from an explosion in the chemical laboratory of the Southern Methodist .University in Dallas. The irregular, gaping wounds extended entirely across the cornea; and as normal approximation was impossible, the problem developed of securing a clostre of the wounds. 
This was accomplished by providing a bridge of bulbar conjunctiva, swung like a hammock across the cornea and retaining its original attachment at either extremity. This conjunctival bridge, carrying its vascular supply was allowed to remain in contact with the wounds until the healing process was completed and then it was carefully dissected away, leaving only linear scars to mark the situation of former gaping wounds.

\section{ABSTRACT OF DISCUSSION}

DR. William M. Sweet, Philadelphia: Dr. McReynolds has so fully covered every phase of the subject of foreign body injuries of the eyejall that there is nothing new to add. It is now generally recognized that the first consideration is to determine whether the body which caused the injury has lodged within the eyeball or orbit, and if within the eye, its position and approximate size. Many injured eyes have been lost in the past by delay in making the diagnosis of a foreign body in the globe, local measures being employed for a considerable period until the metal or other material causing the traumatism was so covered with exudate that attempts at extraction failed. I have always favored the scleral incision for the removal of steel from the vitreous chamber. As most of the particles are at or posterior to the equator of the globe, the body has a shorter distance to travel than if brought around the lens. It is only in the few instances in which the metal is of small size, and with no irregular surfaces to be caught in the anterior uveal tissues, that I have drawn the metal into the anterior chamber.

May experience in retinal detachment following extraction agrees with that of Dr. McReynolds. I have not found the separation at the site of the incision in the sclera but in other portions of the vitreous chamber. In the cases in which detachment occurs, I believe it is due to the contraction of the newly formed inflammatory lesions at the point in the retina or choroid where the parts have been injured by a fairly large body, or, in instances in which a smaller body has remained imbedded for several days or weeks, to the traumatism which has followed the drag of the magnet in loosening the metal from the exudation in which it was imbedded. With the apparent trivial character of so many of these foreign body injuries to the patient and his friends, the ultimate results as to vision are rather unsatisfactory; and yet $I$ fail to see any possible improvement in our present methods of diagnosis or operative procedure. One third of all cases in which there has been perforation of the globe by a foreign body are lost; some from primary infection, some from inability to remove the body, and a larger number from late iridocyclitis. Where extraction has been successful, only a few secure useful vision. Our endeavors, therefore, must be in the direction of earlier diagnosis of a retained foreign body in the eyeball and its prompt removal. This will come with the recognition by the general profession of the serious nature of perforating wounds of the eyeball in workmen in industrial establishments, and earlier consultation with the specialist. It has been my practice in all perforating wounds of the eyeball, especially those of large size, to cover the opening with a conjunctival flap. When an incision is to be made in the sclera for the extraction of steel from the vitreous chamber, a cut is first made in the conjunctiva, the membrane undermined for a short distance, and the edges of the cut held apart by two threads. After extraction of the steel the edges of the cut conjunctiva are closed over the incision in the sclera. I have seen a few cases in which the roentgen rays failed to give a shadow of a foreign body that was in the eyeball. A thin foreign body may be so situated that the edge of the metal is toward the tube, and only a faint line of shadow is cast that may be lost in the shadow of the orbital bones. If the examination points to a probable foreign body in the globe not shown in the first roentgenograms, it is advisable to make additional plates, with the tube in different positions, so that a shadow is secured on the plate free from the shadow of the bones of the orbit.

DR. R. H. T. MANN, Texarkana, Ark.-Texas: Several years ago I began some experimental work to see if the dangers from operations on the interior of the eye could not be much lessened by increasing the air pressure on the outside, thus equalizing the pressure of the interior of the globe and preventing the flow of vitreous from the eye during an operation for the removal of foreign bodies in the vitreous chamber. These experiments have so far been carried on in the thoracic chamber apparatus, at the Lenox Hill Hospital, in New York City. The first steps of the experiments have consisted in trying to ascertain whether both operator and the eye should be in the air tight chamber, or whether the operator should be in the air tight chamber and the patient on the outside of the chamber, with the air pressure exerted against the anterior segment of the eye alone. It seems from the present limited experiments which have been performed that this is along the lines which will have to be adopted, because the pressure in the eye may increase as rapidly as the pressure on the outside which prevents the equalization of the pressure. It is perfectly feasible for the operator, without any difficulty, to remain within the air tight chamber with the pressure increased to the pressure of the normal eye, which is $25 \mathrm{~mm}$. of mercury. The increased blood pressure in the interior of the eye is somewhat offset by the hard coats of the eye, and this will be of considerable assistance in retaining the vitreous within the eye itself. I think that the air pressure can be exerted on the anterior segment of the eye during operations, thereby preventing the loss of vitreous and the collapse of the eye. If this can be done, it will not only simplify very much the removal of foreign bodies from the vitreous chamber, but also render easy other operations on the eye where there is danger of losing the vitreous. The reason why all the vitreous does not escape now is because the pressure becomes equal, and with the patient looking up gravity prevents it from all escaping.

Dr. JoHn GreEn, St. Louis: The possibility of a localized infection of the vitreous immediately surrounding the site of the foreign body suggests one objection to the anterior route. Given an infected foreign body in the vitreous, with the point of entrance in the sclera the patient coming under observation soon after the accident, that method of extraction which, so far as possible, follows the track made by the entering foreign body, should be followed in its extraction. The adoption of any other route means the risk of infecting a previously uninfected track. It is as though we should streak an infected platinum loop along a previously unstreaked surface of the culture medium.

Dr. Edward Jackson, Denver: Many very interesting points have been brought out, and among them $I$ wish to refer to one. The most common and dangerous failure of roentgen-ray localization of foreign bodies in the eye, which I have encountered, has been the report that the foreign body was outside of the eyeball, when it was really within it. I think that probably is due to the fact that sufficient allowance has not been made for the divergence of the rays used in localizing. The rays are always divergent. The amount of divergence depends especially on the distance it is from the eye. Most men using the diagrams which have been prepared for this purpose are not at first inclined to take that into account. Such diagrams should have printed on them some reference to it. If the diagram represents the exact size of the eyeball, and is intended to represent in millimeters the exact position, there should be a table indicating the increase of dimensions, which would be caused by using the tube at six inches, eight inches, ten inches, etc. The printing of something of that kind on the diagram will call the attention of the roentgenologist and the surgeon to the fact that the negative obtained shows the part magnified.

Dr. W. M. SweEt, Philadelphia: On the charts for plotting the position of the foreign body, allowance is made for the divergence of the roentgen rays. If the body is of large size, it is customary to localize the two ends. A slight error is possible in foreign bodies at the posterior part of the vitreous, owing to the injured eye being larger or smaller than the diagrammatic eyeball of the chart, which measures $24 \mathrm{~mm}$. Accuracy of localization depends on the determination of the distance of the indicating ball of the apparatus from the center of the cornea. If the roentgenographer fails 
to carefully make the measurements the localization of the foreign body will be inaccurate.

Dr. Allen Grfenwoon, Boston: I trust the few brief remarks I will have to offer will never again be applicable. Never again do we want to go through the experiences we have been through, but if, perchance, some of you are called on to do work such as was done in the last few years in France, you will find that handling these cases in the military organization is entirely different from the civilian method in many ways. In the hurry of work in mobile and evacuation hospitals, it is difficult to get roentgen-ray work done with accuracy and speed. Therefore, in removing foreign bodies the magnet, besides the work of removal, is of great service from a diagnostic standpoint and it should be thus used. If a foreign body is demonstrated it possibly can be brought into the anterior chamber and then removed with the smaller magnet. I would call your attention to the magnet we used most in France, which weighs nearly sixty pounds, the large one of Dr. Lancester, which has practically the same pull as the giant Haab. The question of the removal of foreign bodies by the posterior route or by the anterior route, so-called, will probably never be settled as some men would prefer one and some the other. Both methods are useful but both have limitations. I extracted most of the foreign bodies I saw through the posterior route, only removing very small ones by the anterior route.

I want to add a word in regard to the use of the conjunctival fap. Some of you have seen Military Manual No. 3 in which you will find advocated the use of the conjunctival flap and the hammock flap of Dr. N. C. Reynolds, which have been used for covering the central wounds of the eyes and with excellent results.

Dr. Lee M. Francis, Buffalo: I want to emphasize what Dr. Sweet brought out, that is, taking pictures of the suspected foreign body from more than one direction. In one case in Base Hospital No. 115, in which we selected an anterior route as the roentgenogram gave us the idea that it was a small one, instead of having a round body, we had a spicule of steel four millimeters in length. We should have used the posterior route and we would not have lost it. We must be sure of the third dimension of the foreign body.

Dr. George S. Derby, Boston: During eight months of the time I was in France $I$ had the opportunity of working in the principal eye base at Boulogne. At least 500 foreign bodies in the eyes were treated. I had an opportunity of talking with a number of French surgeons who were treating this class of cases. The British are strongly in favor of the extraction by the anterior route, and that was the principal mode of operation in France by them. The French, however, used the anterior route in some cases and the posterior route in others. You may have a foreign body when there is no sign of a perforation, or none is visible, at least. Do not overlook that. It must not be thought because you have no sign of entrance that it is not there. The roentgen ray is a fine test, but the final test is the magnet. The giant magnet should be used in all doubtful cases. I believe small foreign bodies measuring less than one millimeter should be extracted by the giant magnet by the anterior route. The British used it for larger pieces. If you cannot get a small body in one sitting, try it again, either the same day or the following day. I have seen a number of cases where it was not brought forward until three or more trials, and then it was successfully extracted. Sometimes we are in doubt as to whether the foreign body is in the eye or has passed through the eyeball. Where the -perforation is complete one gets an evident degree of proptosis of the eyeball, and this I believe is an excellent diagnostic sign.

Dr. E. E. Holt, Portland, Me.: When I presented my first series of cases of removal of foreign bodies from the interior of the eye to the American Ophthalmologic Society, more than thirty years ago, some of the members were sure that disastrous results would follow this practice. This series of cases, as well as the second series of cases presented to this society, and all of my subsequent cases, were followed as carefully as it was possible to follow their subsequent history without finding that this practice did lead to dis- astrous results. The diagnosis of all my cases in the first two series of cases presented to the American Ophthalmologic Society was made from the circumstance of the accident, the size and location of the wound in the eye, electromagnet and the ophthalmoscope. When the foreign body could not be detected by the ophthalmoscope there was no more difficulty experienced in removing the metal than when it could be readily scen. When the wound was small or was located in the cornea, the metal was removed by making a flap of the conjunctiva and an incision into the eyeball in the inferior outer quadrant, using a medium sized hand magnet for its extraction. My experience teaches me that time is an element of the greatest importance in the successful removal of foreign bodies from the interior of the eye, there being much less reaction when it is removed on the same day of the accident than at any subsequent time. This is of so much importance that I should prefer to operate without a roentgen-ray examination if I could not get one right away after the case came under my care provided I was quite sure the foreign body was in the eye. As the essayist says "watchful waiting" will not do, something must be done to remove the foreign body from the eye if we are to treat these cases successfully. When my first series of cases was presented to the American Ophthalmological Society, some of the members expressed surprise that I should have so many more cases than the rest of the members. The explanation made at the time was that I began the practice of removing the foreign body from the interior of the eye, thus saving the eye with sight instead of removing the eye, as had been expected by all concerned, and insisted that it should be done at the earliest moment possible after the accident. This practice becoming generally known among those liable to these accidents, they lost no time in having it carried out at once. The reason why the other members of the society had so few cases at that time came from the fact that it was taught that when an eye was injured by metal penetrating it, in what had been designated the "dangerous zone," and the metal remained in the eye, the eye should be removed. This was done by the general surgeon. Thus the specialist did not see many of these cases. When, however, it became more generally known that a foreign body could be removed, thus saving the eye with sight, the specialist was consulted and he began to have cases commensurate with accidents of this nature.

Dr. Oliver Tydings, Chicago: For some years we had the first and only giant magnet west of the Allegheny Mountains, and in that time we have had a great number of injuries. We came to look on the giant magnet as being an infallible diagnostic instrument; but our delusion was dispelled, and not with a case tried once or twice, but frequently; not by one man, but by three of the most competent men in the profession, until we discovered that the roentgen ray disclosed what a giant magnet would not. And we are able to locate the pieces of steel with the roentgen ray that we could not with the giant magnet. I do not know why, but there are times when iron or steel is diamagnetized, and you will have that experience. With regard to the localization, it is very important. I can recall a case localized behind the globe which I dij not disturb, and it got well with good visual acuity; but that case is a sad commentary on the neglect of treatment afterwards. In this case a foreign body had passed through the globe, injuring the lens, which was absorbed. Vision after several months with correction was $20 / 20$. When next seen a quiet iritis had distorted the pupil, which interfered greatly with vision and $22 / 100$ was the best that could be obtained until after the long use of scopolamin the vision was again brought to practically normal. On account of its position, no attempt was made to find out what the foreign body was. I think it was a shot, and is still posterior to the globe and doing no damage.

Dr. John O. McReynolds, Dallas, Texas: An important question arises as to the magnetic quality of various alloys of iron, and it is well known that a high percentage of manganese may render the iron nonmagnetic and hence in such cases the magnet would be of no value either in diagnosis or in operation. One of the most difficult problems in connection with these cases is presented after the foreign body 
has been successfully removed. It is this, how long are we justified in persisting in our efforts to save a seriously wounded eyc? My own conviction is that if the eye is going to do any good this fact will be inclicated within a period of three weeks and further delay may unnecessarily imperil the uninjured eye.

\section{THE MAXIMUM PHYSIOLOGIC LYM- PHATIC REACTION IN DEEPLY PENETRATING WOUNDS OF THE EYEBALL}

\author{
E. L. JONES, M.D. \\ CUMLERLAND, MD.
}

While the deep tissues of the eyeball are among the hody's structures most highly susceptible to infection from penetrating wounds, they have profited very little by the great principles of wound sterilization as developed by modern antisepsis, and eyes so injured are daily being removed, as compound fractures of extremities in the old days were followed by amputations to save the patient from death from sepsis. This is true because the delicate structures of the eye cannot stand any really efficient germicide. Nor can such be given free access to the seat of infection, nor can the parts be laid open for free drainage, nor can damaged tissues be cut away as in recent war surgery.

How, then, may this situation be altered for the better? The answer is to be found in exciting an abundant flow of lymph, which is nature's antiseptic and tissue restorer, and goes to every part of the eye that a germ can reach. There may be other ways of producing this reaction, but the one that I have employed for a number of years is a massive subconjunctival injection of mercuric cyanid in conjunction with certain other drugs, by which the subconjunctival spaces on the ball, and the loose tissues of the lids are speedily distended to their utmost with lymph, preventing in most instances the lids' being opened for several days, and often causing swelling even on the face. How much lymph circulates through the tissues is not known; but the amount which transudes out can easily be told by squeezing out a pad which has been on an eye for twenty-four hours, after having been wet with about 2 ounces of water. If to this be added nitric acid, it will curdle so that it is as dense as buttermilk.

In my experience, covering fifteen years, all manner of extensive, and deep penetrating wounds, many attended by nonrecoverable foreign bodies, have healed with no signs whatever of infection, or of degeneration or damage aside from the initial injury. In a paper on "Foreign Bodies Within the Eyeball," read before the Section on Ophthalmology at the recent session of the American Medical Association, Dr. McReynolds ${ }^{1}$ states that the victory has not been won when the foreign body has been brilliantly extracted, and anxious days of waiting in fear of sepsis follow. He speaks of the slow degenerative changes which may follow after months or years, including detachment of the retina.

It was said by Dr. Herman Knapp, in the early days of giant magnet extraction, that these cases made a grand impression at first, but that many patients ultimatcly became blind. Mr. Gustavus Hartridge ${ }^{2}$ says,

\footnotetext{
1. McReynolds, J. O.: Foreign Bodies Within the Eyeball, J. A. M. A., this issue, p. 818.
2. Martridge, Gustavus: Tr. Ophth. Soc. U. K., 1915, Vol. XXXV, p. 125 .
}

in discussing this subject before the Ophthalmological Society of the United Kingdom in 1915:

The patient appears to make an excellent recovery, and leaves the hospital with perhaps almost normal vision; months later the vision of the eye gradually fails, and on examination, a large detachment is found. I have seen dozens of such cases, and would venture to state that the majority of cases in which a foreign body is removed from the back of the eye through the vitreous end this way.

Another prolific source of destruction, in my belief, is the organization and shrinking of profuse vitreous hemorrhage. It is my contention that all of these patients should be given the massive cyanid injection which sterilizes the eye, furnishes lymph to repair damaged tissue, and promotes absorption of blood effused into the vitreous. Furthermore, the swelling of the conjunctiva closes and covers the wounds, and protects them from conjunctival secretions, serving the purpose of the double flap suture advocated by Francis, and the sliding flap operation recommended in the official Military War Manual No. 3 on ophthalmic surgery.

A number of oculists who have used the injection in cases of intractable diseases have found that it serves them well; let us hope it will be given the same trial in cases of deeply penetrating wounds, and the wounds attendant on magnet operations.

Dr. McWhinnie ${ }^{3}$ has detailed a series of phenomenal results from these injections, among them an extensive scleral wound made by a dirty fish knife, presenting a condition for which textbooks advise immediate enucleation, in which the eyeball and vision were saved by the injection. I have in sundry publications pleaded for the single massive injection instead of frequent small or salt water injections, and have had my beliefs confirmed by men who have used the plan advocated. The detractors are found among those who use the small or mild injection, and fail to excite the maximum physiologic lymphatic reaction.

\section{A SECOND ATTACK OF SYPHILIS TWO YEARS AFTER THE FIRST}

\author{
CURABILITY OF THE DISEASE * \\ JAY FRANK SCHAMBERG, M.D.
} PHILAJELPHIA

In view of the fact that the Wassermann reaction is not inf requently negative in the presence of indubitable evidence of active syphilis, in the minds of many, this query has arisen: "How can we ever be sure of the complete extinction of the disease?" Indeed, many physicians have expressed doubts as to its curability. It is important for the profession to have placed before it as much convincing evidence pointing to the radical extermination of the syphilitic infection as possible, in order that there may be developed a crystallized scientific judgment on this important question. There is every reason to believe that many patients treated intensively in the early primary stage are cured, for they commonly remained free of symptoms for years and repeatedly have negative blood tests. But these data do not of themselves constitute evidence of cure.

\footnotetext{
3. McWhinnie, New York M. J. 107: 343 (Feb. 23) 1918. * Read before the Section on Dermatology at the Seventieth Annual Session of the American Medical Association. Atlantic City, N. J., Jume, 1919.
} 